\title{
Editorial
}

\section{Disc replacement versus fusion}

Tsung-Hsi Tu, M.D., ${ }^{1-3}$ John E. Ziewacz, M.D., M.P.H, ${ }^{1}$ and Praveen V. Mummaneni, M.D. ${ }^{1}$

${ }^{1}$ Department of Neurosurgery, University of California, San Francisco, California; ${ }^{2}$ Department of Neurosurgery, Neurological Institute, Taipei Veterans General Hospital; and ${ }^{3}$ School of Medicine, National Yang-Ming University, Taipei, Taiwan

Spinal total disc replacement (TDR) has been proposed as a viable alternative to standard spinal arthrodesis to treat degenerative disc disease. The major theoretical advantage of TDR is motion preservation and possibly less biomechanical stress on adjacent levels. In this issue of the Journal of Neurosurgery: Spine, Zigler and colleagues ${ }^{6}$ reported on a post hoc 5-year follow-up evaluation of adjacent-level degeneration (ALD) in a prospective randomized trial involving 161 patients undergoing TDR (ProDisc-L, Synthes Spine, Inc.) and 75 patients undergoing circumferential lumbar fusion (anterior lumbar interbody fusion with femoral ring allograft and posterior pedicle screw fusion). These authors radiographically graded disc height loss, endplate sclerosis, osteophyte formation, and spondylolisthesis at 5 years postoperatively and found that $9.2 \%$ of the TDR patients and $23.8 \%$ of the fusion patients had ALD. This finding was statistically significant. It is noteworthy that only $76.4 \%$ of the TDR patients and $57.3 \%$ of the fusion patients had complete 5-year radiographic follow-up data available for analysis.

There are several interesting findings in this report. First, the reoperation rates for adjacent-level disease are not significantly different between the 2 treatment groups despite the significant difference in radiographic ALD rates. The authors reported that $1.9 \%$ of the TDR group and $4.0 \%$ of the circumferential fusion group had adjacent-level surgery during the follow-up period $(\mathrm{p}=$ 0.68 ). Furthermore, the changes associated with ALD did not correlate with clinical outcome parameters. Interestingly, there were no significant changes in the preoperative versus 5 -year postoperative range of motion (ROM) at the superior adjacent level in either group. At the inferior adjacent level, both groups demonstrated an increased ROM, but only the TDR group reached statistical significance. It was not clear in this study if the superior or the inferior adjacent level is more prone to ALD changes.

This study seems to contradict the concept that fusion can increase ROM in adjacent levels and contribute to ALD. ${ }^{1}$ Besides changes in spinal biomechanics, several other factors that may contribute to ALD have been proposed, including superior facet violation, osteoporosis, posterior instrumentation, advanced age, preexisting adjacent-level disease, or fusion length. The interactions between these factors in the development of ALD remain elusive..$^{2-5}$

In summary, the authors showed that at the 5-year follow-up, reoperation rates for adjacent-level disease were not different between the TDR group and circumferential fusion group despite findings that radiographic adjacent degeneration is more prevalent in the fusion group. The longer follow-up and more sophisticated analysis of patients involved in investigational device exemption (IDE) trials such as this one will provide the basis for further understanding of this interesting and important topic in the years to come.

(http://thejns.org/doi/abs/10.3171/2012.8.SPINE12709)

\section{Disclosure}

Dr. Mummaneni is a past consultant for DePuy and receives royalties from DePuy, Quality Medical Publishing, Inc., and Thieme Medical Publishers, Inc.

\section{References}

1. Berg S, Tropp HT, Leivseth G: Disc height and motion patterns in the lumbar spine in patients operated with total disc replacement or fusion for discogenic back pain. Results from a randomized controlled trial. Spine J 11:991-998, 2011

2. Berg S, Tullberg T, Branth B, Olerud C, Tropp H: Total disc replacement compared to lumbar fusion: a randomised controlled trial with 2-year follow-up. Eur Spine J 18:1512-1519, 2009

3. Ekman P, Möller H, Shalabi A, Yu YX, Hedlund R: A prospective randomised study on the long-term effect of lumbar fusion on adjacent disc degeneration. Eur Spine J 18:11751186, 2009

4. Harrop JS, Youssef JA, Maltenfort M, Vorwald P, Jabbour P, 


\section{Editorial}

Bono CM, et al: Lumbar adjacent segment degeneration and disease after arthrodesis and total disc arthroplasty. Spine (Phila Pa 1976) 33:1701-1707, 2008

5. Hilibrand AS, Robbins M: Adjacent segment degeneration and adjacent segment disease: the consequences of spinal fusion? Spine J 4 (6 Suppl):190S-194S, 2004

6. Zigler JE, Glenn J, Delamarter RB: Five-year adjacent-level degenerative changes in patients with single-level disease treated using lumbar total disc replacement with ProDisc-L versus circumferential fusion. Clinical article. J Neurosurg Spine [epub ahead of print October 19, 2012. DOI: 10.3171/ 2012.9.SPINE11717]

\section{Response}

Jack E. Zigler, M.D. ${ }^{1}$ And Rick B. Delamarter, M.D. ${ }^{2}$

${ }^{1}$ Texas Back Institute, Plano, Texas; and ${ }^{2}$ Cedars-Sinai Spine Center, Los Angeles, California

We appreciate the comments made by Drs. Tu, Ziewacz, and Mummaneni, as we all learn while observing these FDA IDE study cohorts over longer time intervals.

Although there was no statistically significant difference in surgical intervention between the fusion and arthroplasty groups during this first 5-year window, most clinicians would not expect to see a significant difference in this relatively short time, particularly with only single-level involvement. The key question is whether the statistically significant ALD difference we found at 5 years will evolve into clinically significant adjacent-level disease, necessitating additional reconstructive surgery as time goes on. That will be the true "ah ha" moment that may tip the scales in favor of arthroplasty, but that difference above single-level interventions may take another 5or even a 10-year window. Similar analyses of our 2-level study cohorts, currently being developed, may provide earlier information.

In that vein, we encourage the scientific community to strongly recommend to commercial sponsors of these multicenter prospective IDE studies that they dig in for the long haul and commit to studying these patient cohorts for 10,15 , and even 20 years from the time of surgery. This will represent a large cost to the sponsors (for institutional review board approvals, patient followup, data management, and so forth) that may not directly translate back into commercial sales, but this unique academic opportunity to follow fusion and arthroplasty patients longitudinally should not be wasted. It is an opportunity we are not likely to see again, and demand from the surgeon community is the only way that this longterm data can be mined.

This dovetails precisely with the authors' editorial comment that the "longer follow-up and more sophisticated analysis of patients involved in IDE trials such as this one will provide the basis for further understanding of this interesting and important topic in the years to come." We could not agree more.

Please include this information when citing this paper: published online October 19, 2012; DOI: 10.3171/2012.8.SPINE12709. 